\title{
Combined Mammographic and Sonomammographic Evaluation of Breast Masses
}

\author{
Kiranmai Runjjala ${ }^{1}$, Y. Tatayya Naidu ${ }^{2}$ \\ ${ }^{1}$ Assistant Professor, Department of Radio Diagnosis, Government Medical College, Srikakulam, ${ }^{2}$ Assistant Professor, \\ Department of Radiodiagnosis, Konaseema Institute of Medical Sciences, India
}

Corresponding author: Dr Kiranmai Runjjala, Department of Radio Diagnosis, Government Medical College, Srikakulam, Andhra Pradesh 532001, India

DOI: http://dx.doi.org/10.21276/ijcmsr.2020.5.1.36

How to cite this article: Kiranmai Runjjala, Y. Tatayya Naidu. Combined mammographic and sonomammographic evaluation of breast masses. International Journal of Contemporary Medicine Surgery and Radiology. 2020;5(1):A162-A165.

\section{A B S T R A C T}

Introduction: Breast cancer is the most common cause of cancer death in women and an overall fifth common cause of cancer deaths. Triple assessment of clinical examination, breast imaging and needle biopsy remain the mainstay of a breast cancer diagnosis. Among imaging techniques mammography helps in diagnosing asymmetry, neodensity, distortion of fibroglandular architecture and USG plays a key role in differentiating cystic and solid masses. The present study evaluated palpable breast masses using mammography and ultrasound and compared them with histopathological results.

Material and methods: A cross-sectional study was conducted at tertiary care hospital, which included sixty women more than or equal to 30 years with abnormalities of the breast such as palpable lump, thickening, nodularity were included in the study. After taking informed written consent the patients underwent the study, both mediolateral oblique and craniocaudal views were obtained followed by ultrasonographic evaluation. HPE was considered as gold standard and results were compared with image finding.

Results: Majority were in the age group (40\%) between $41-50$ years. The most common clinical complaint was $53.33 \%$ palpable lump. Image findings reported $42.22 \%$ of benign lesions and $13.33 \%$ were suspicious lesions. On histopathological examination $34.62 \%$ were malignant and $65.38 \%$ were benign lesions. The diagnostic accuracy of imaging findings in predicting HPE was $85.71 \%$. The sensitivity and specificity of the image finding is $83.33 \%$ and $76.47 \%$ respectively.

Conclusion: Combined use of mammography and sonography is appropriate in most instances to characterize palpable lesions and avoids unnecessary interventions and biopsies.

Keywords: Breast Masses, Histopathology, Mammographic, Sonomammographic.

\section{INTRODUCTION}

Breasts are a secondary sexual characteristic in females. They are also the source of nutrition for the neonate and thus of mankind. This tender, sensitive and delicate complex structure is constantly under the influence of hormones. ${ }^{1,2}$ Any aberration in this process leads to the susceptibility to a spectrum of localised pathologies like hyperplastic and neoplastic changes. Of the various pathologies that afflict the breast, cancers are most often encountered and are the most dreaded. ${ }^{3}$ Breast cancer is the most common cause of cancer death in women and an overall fifth common cause of cancer deaths in the world. Incidence of breast cancer as per the ICMR studies show that one in every 22 women is likely to suffer from breast cancer. Incidence has almost doubled in the last 24 years and it is expected to increase per year by $3 \%$. It is responsible for $20 \%$ of cancer-related deaths in women. ${ }^{4}$ Triple assessment of clinical examination, breast imaging and needle biopsy remain the mainstay of a breast cancer diagnosis. The standard technique of breast imaging includes screen film X-Ray mammography and real-time ultrasound.
Other techniques are MRI, Colour Doppler, contrastenhanced ultrasound, scientist mammography and digital mammography. ${ }^{5}$

The incidence of breast cancer deaths can be reduced by $30 \%$ by the routine screening of healthy women with Mammography. This is because breast changes like asymmetry, neodensity, distortion of fibroglandular architecture and microcalcifications are picked up earlier than lesions that become clinically palpable, or are sometimes detected by self-examination. ${ }^{6}$ USG plays a key role in differentiating cystic and solid masses. ${ }^{7}$ It is useful in the evaluation of palpable masses not visible in radiographically dense breasts, abscesses, masses that are not completely evaluable with MG and in young patients susceptible to radiation damage.

The sensitivity of mammography alone is between $45 \%$ and $90 \%$ depending on a number of factors including age and breast density. The sensitivity of ultrasound alone is generally reported as being $80-90 \% .{ }^{8}$ The Royal College of Radiologists guidelines also recommend the use of ultrasound as an adjunct to mammography in patients of all ages, although no explicit guidance is given. ${ }^{9}$ 
Keeping in view, the limitations of individual modalities, we aimed in our study to evaluate palpable breast masses using mammography and ultrasound than either method along and compared them with histopathological results.

\section{MATERIAL AND METHODS}

The study was conducted at tertiary care hospital which included ninety women more than or equal to 30 years referred to this centre with abnormalities of the breast during a period of 18 months between January 2015 and December 2017. Abnormalities of the breast with a variety of clinical descriptions, such as palpable lump, thickening, nodularity were included in the study. Abnormalities of sufficient clinical concern to be referred for imaging evaluation were studied.

Women below 30 years of age with palpable abnormalities, breasts with fungating mass per breast and mass adherent to the chest wall, where performing mammography was difficult were excluded from the study.

Time of initial visit, date of initial visit, age of the patient, site of the palpable abnormality and description of the abnormality were documented. After taking the informed written consent of the patient or her relative, patients were subjected to breast examination. Then patients underwent mammography in the presence of a female attendant. Both mediolateral oblique and craniocaudal views were done of each breast after firm compression. Mammography was performed with GE SENOGRAPHE DMR equipment. The mammographic assessment was followed by ultrasonographic evaluation of breast using a real-time scanner (Philips Envisor C 0.2) with a 7 to $10 \mathrm{MHz}$ broadband linear array probe with a breast present. Each quadrant of the breast with lesion was scanned in radial and antiradial planes. Both breasts were scanned in every case for comparison. Axilla was also scanned for any enlarged lymph nodes.

HPE (Histopathological Examination) was considered as gold standard and results obtained from HPE were compared with mammography and ultrasonic finding. The sensitivity, specificity, predictive values and diagnostic accuracy of the screening test along with their 95\% CI were presented. $\mathrm{P}$-value $<0.05$ was considered statistically significant. IBM SPSS version 22 was used for statistical analysis. ${ }^{10}$

\section{RESULT}

A total of 90 subjects were included in the final analysis. Among the study population, 20 (22.22\%) participants belong to 30 to 40 years age group, 36 (40\%) were in 41 to 50 years age group, $22(24.45 \%)$ were in 51 to 60 years age group and $12(13.33 \%)$ were aged $>60$ years. (Table 1 )

Among the study population, 48 (53.33\%) participants had a palpable lump, 10 (11.11\%) participants had Palpable thickening and 14 (15.56\%) participants had nodularity. When breast parenchymal density pattern is observed, 38 (42.22\%) participants had scattered fibro glandular density, 25 (27.78\%) participants had Predominantly Fatty breast, 15 (16.67\%) participants had dense breast and 12 (13.33\%) participants had heterogeneously dense breast. (Table 2)

The frequency of benign lesions was $42.22 \%$ and suspicious lesions were $17.78 \%$. On histopathological examination
26.92\% were malignant and $73.08 \%$ were benign lesions. Among malignant lesions majority was $64.24 \%$ were Ductal carcinoma, 21.42\% were Lobular carcinoma, 7.14\% were Mucinous and Mixed carcinoma. Among benign lesions cysts were 44.73\%, Fibroadenomas were 23.68\%, Duct Ectasia and Fibrocystic diseases were $13.15 \%$ and Lipomas were $5.26 \%$. (Table 3 )

When imaging findings and HPE were compared with each other $85.71 \%$ were malignant lesions and $89.47 \%$ were benign lesions and it was statistically significant. (Table 4)

The diagnostic accuracy of imaging findings in predicting HPE was $85.71 \%$. The sensitivity and specificity of the image finding is $85.71 \%$ and $89.47 \%$. Positive predictive

\begin{tabular}{|l|c|c|}
\hline Age Groups & Frequency & Percentages \\
\hline $30-40$ & 20 & $22.22 \%$ \\
\hline $41-50$ & 36 & $40.00 \%$ \\
\hline $51-60$ & 22 & $24.45 \%$ \\
\hline$>60$ & 12 & $13.33 \%$ \\
\hline \multicolumn{2}{|c|}{ Table-1: Descriptive analysis of age in groups in the study } \\
population (N=90) \\
\hline
\end{tabular}

\begin{tabular}{|l|c|c|}
\hline Descriptor & Frequency & Percentages \\
\hline Palpable lump & 48 & $53.33 \%$ \\
\hline Palpable thickening & 10 & $11.11 \%$ \\
\hline Nodularity & 14 & $15.56 \%$ \\
\hline Not specified & 18 & $20.00 \%$ \\
\hline Breast Parenchymal Density \\
\hline Scattered fibro glandular Density & 38 & $42.22 \%$ \\
\hline Predominantly Fatty & 25 & $27.78 \%$ \\
\hline Dense & 15 & $16.67 \%$ \\
\hline Heterogeneously Dense & 12 & $13.33 \%$ \\
\hline Table-2: Descriptive analysis of clinical and mammography \\
findings (N=90) \\
\hline
\end{tabular}

\begin{tabular}{|l|c|c|}
\hline & Frequency & Percentages \\
\hline Imaging findings (N=90) & & \\
\hline Negative & 38 & $42.22 \%$ \\
\hline Benign & 36 & $40.00 \%$ \\
\hline Suspicious & 16 & $17.78 \%$ \\
\hline HPE findings ( $\mathrm{n}=52$ ) & & \\
\hline Malignant & 14 & $26.92 \%$ \\
\hline Benign & 38 & $73.08 \%$ \\
\hline Benign lesions (N=38) & & \\
\hline Cysts & 17 & $44.73 \%$ \\
\hline Fibroadenoma & 9 & $23.68 \%$ \\
\hline Duct ectasia & 5 & $13.15 \%$ \\
\hline Fibrocystic disease & 2 & $13.15 \%$ \\
\hline Lipoma & 9 & $5.26 \%$ \\
\hline Malignant (N=14) & 3 & $64.28 \%$ \\
\hline Ductal carcinoma & 1 & $21.42 \%$ \\
\hline Lobular carcinoma & 1 & $7.14 \%$ \\
\hline Mucinous carcinoma & 5. & $7.14 \%$ \\
\hline Mixed carcinoma & population & \\
\hline Table-3: Descriptive analysis of Imaging findings in the study & \\
\hline
\end{tabular}




\begin{tabular}{|c|c|c|c|c|}
\hline \multirow[t]{2}{*}{ Imaging Findings } & \multicolumn{2}{|c|}{ HPE } & \multirow[t]{2}{*}{ Chi-square } & \multirow[t]{2}{*}{ P-value } \\
\hline & Malignant ( $\mathrm{N}=14$ ) & Benign $(\mathrm{N}=38)$ & & \\
\hline Malignant & $12(85.71 \%)$ & $4(10.53 \%)$ & \multirow[t]{2}{*}{27.151} & \multirow[t]{2}{*}{$<0.001$} \\
\hline Benign/Negative & $2(14.29 \%)$ & $34(89.47 \%)$ & & \\
\hline
\end{tabular}

\begin{tabular}{|l|c|c|c|}
\hline \multirow{2}{*}{ Parameter } & \multirow{2}{*}{ Value } & \multicolumn{2}{|c|}{$95 \% \mathrm{Cl}$} \\
\cline { 3 - 4 } & & Lower & Upper \\
\hline Sensitivity & $85.71 \%$ & $57.19 \%$ & $98.22 \%$ \\
\hline Specificity & $89.47 \%$ & $75.20 \%$ & $97.06 \%$ \\
\hline False positive rate & $10.53 \%$ & $2.94 \%$ & $24.80 \%$ \\
\hline False negative rate & $14.29 \%$ & $1.78 \%$ & $42.81 \%$ \\
\hline Positive predictive value & $75.00 \%$ & $47.62 \%$ & $92.73 \%$ \\
\hline Negative predictive value & $94.44 \%$ & $81.34 \%$ & $99.32 \%$ \\
\hline Diagnostic accuracy & $88.46 \%$ & $76.56 \%$ & $95.65 \%$ \\
\hline Table-5: Predictive validity of imaging findings in predicting \\
HPE (N=52) \\
\hline \multicolumn{3}{|c|}{} \\
\hline
\end{tabular}

value, negative predictive value, False positive rate, and False-negative rate are $75.00 \%, 94.44 \%, 10.53 \%$ and $14.29 \%$ respectively. (Table 5)

\section{DISCUSSION}

Breast cancer is the commonest cause of cancer mortality in females. Breast masses are common in female and amongst all the breast masses, malignant masses are the most feared. ${ }^{11}$ The age group of 90 females varied from 30 to more than 60 years with maximum no. of cases being in the age group (40\%) were aged between 41-50 years. It is in accordance with the study conducted by Ohri $\mathrm{P}$ et $\mathrm{al}^{12}$, where the majority of them were in the age group 41 to 50 years.

The most common clinical complaint was $53.33 \%$ palpable lump. The mammographic parenchymal pattern of the breast according to Tabar's classify cation (42.22\%) participants had scattered fibro glandular density which supports the theory that young virgin breast contains denser connective tissue. With progression in age, the dense breast becomes mixed glandular pattern tissue, and with further progression in age, breast begins to involute into fatty tissue. Whereas in a study conducted by Prasad SN et a ${ }^{13}, 17.74 \%$ reported fibro glandular density of the breast.

In young women and women with dense breasts, ultrasound appears superior to mammography. Dense fibro glandular tissue is the most important inherent limitation of mammography in the diagnosis of breast cancer. Bilateral whole-breast US can be an effective adjunct imaging examination in the evaluation of women with dense breast tissue. $^{14}$

Image findings reported $40 \%$ of benign lesions and $17.78 \%$ were suspicious lesions. On histopathological examination $26.92 \%$ were malignant and $73.08 \%$ were benign lesions. Among malignant lesions majority was $64.28 \%$ were Ductal carcinoma. Among benign lesions cysts were 44.73\%, fibroadenomas were $23.68 \%$, duct ectasia and fibrocystic diseases were $13.15 \%$ and lipomas were $5.26 \%$. According to Ghebriwet $\mathrm{M}$ et $\mathrm{al}^{15}, 23.68 \%$ had fibroadenoma, $13.15 \%$ had fibrocystic diseases and among malignant lesions, 46.6\% had ductal carcinoma. Similarly, Murphy IG et $\mathrm{al}^{16}$ reported
$64.28 \%$ of ductal carcinoma which is line with our study. On mammography, it was not possible to determine whether the lesion was solid or cystic. Cases of fibrocystic disease of breast were falsely diagnosed as being malignant. On ultrasound, out of 60 lesions, 3 were cystic. In our study, it was possible to correctly diagnose such cases with $100 \%$ accuracy with ultrasound. This was consistent with other studies in which accuracy of ultrasound to diagnose cystic lesions varied from 96-100\%. ${ }^{8,17}$ However with mammography it was not possible to differentiate these 3 cases of simple cysts from fibroadenomas.

MG can help physicians determine whether a lesion is potentially malignant and also screen for occult disease in the surrounding tissue. On mammography, features in favour of benign lesions included well defined smooth margins, oval or round shape and normal breast architecture (24/26). On the other hand, ill-defined speculated lesions taller than wider lesions, architectural distortion, are the features suggestive of malignancy (9/9).

In the current study when imaging findings and HPE were compared with each other $81.82 \%$ were malignant lesions and $87.5 \%$ were benign lesions and it was statistically significant. The sensitivity and specificity of the image finding is $85.71 \%$ and $89.47 \%$. Positive predictive value, negative predictive value, False positive rate, and False-negative rate are $75.00 \%$, $94.44 \%, 10.53 \%$ and $14.29 \%$ respectively. The results of several studies conducted by Kolb TM et al. ${ }^{18}$ Flobbe K et $\mathrm{al}^{19}$ have demonstrated that the addition of ultrasound to mammography has raised the sensitivity of imaging in breast carcinoma to $94-97 \%$. Moss $\mathrm{HA}$ et $\mathrm{al}^{20}$, reported sensitivity of $94.2 \%$ and specificity of $67.9 \%$ in 368 patients in whom combined mammographic and sonographic evaluation had been performed for palpable breast abnormalities and who underwent surgical biopsy. Shetty MK et $\mathrm{al}^{21}$, findings reported a sensitivity of $100 \%$ and specificity of $80.1 \%$ in patients with palpable breast lumps. The high negative predictive value (91.3\%) provides evidence to support the interpretation that two tests combined can reliably identify the case.

In our study, 14 (26.92\%) of 90 lesions were categorized as benign and malignant after a combined mammographic and sonographic evaluation, clearly showing the value of imaging in helping avoid unnecessary biopsies.

\section{CONCLUSION}

In conclusion, imaging has an important role in the management of palpable abnormalities of the breast. The combined use of mammography and sonography is appropriate in most instances to characterize palpable lesions and to avoid unnecessary interventions in those cases in which imaging findings are unequivocally benign. 


\section{ACKNOWLEDGMENT}

We acknowledge the technical support in data entry, analysis and manuscript editing by "Evidencian Research Associates."

\section{REFERENCE}

1. Clarke D, Sudhakaran N, Gateley CA. Replace fine needle aspiration cytology with automated core biopsy in the triple assessment of breast cancer. Ann R Coll Surg Engl. 2001;83(2):110-2.

2. Schoonjans JM, Brem RF. Fourteen-gauge ultrasonographically guided large-core needle biopsy of breast masses. J Ultrasound Med. 2001;20(9):967-72.

3. Bland KI, Copeland EM, III. The breast: comprehensive management of benign and malignant diseases. 2nd ed. Philladelphia: WB Saunders; 1998.

4. Parkin DM, Bray F, Ferlay J, Pisani P. Estimating the world cancer burden: Globocan 2000. Int J Cancer. 2001;94(2):153-6.

5. Sutton D. Textbook of Radiology and Imaging - 2 vol set IND reprint. 7th ed. New Dehli, India: Elsevier; 2002.p. 1800.

6. Kerlikowske K, Smith-Bindman R, Ljung BM, Grady D. Evaluation of abnormal mammography results and palpable breast abnormalities. Ann Intern Med. 2003;139(4):274-84.

7. Fisher PR, Young BY, Dipietro JP, Malhotra A. Ultrasonography in breast cancer [Internet]. WebMD LLC; 2017 [cited 2020 Jan 20]. Available from: https:// emedicine.medscape.com/article/346725-overview.

8. Berg WA, Gutierrez L, NessAiver MS, Carter WB, Bhargavan M, Lewis RS, et al. Diagnostic accuracy of mammography, clinical examination, US, and MR imaging in preoperative assessment of breast cancer. Radiology. 2004;233(3):830-49.

9. Royal College of Radiologists (Great Britain) Faculty of Clinical Radiology Board. Guidance on Screening and Symptomatic Breast Imaging. 2nd ed. London: Royal College of Radiologists; 2003. p. 29.

10. IBM Corp. Released 2013. IBM SPSS Statistics for Windows, Version 22.0. Armonk, NY: IBM Corp.

11. World Health Organization. "Fact Sheet No. 297: Cancer, " [Internet]. Scientific Research Publishing; 2006. [cited $2020 \mathrm{Jan} 15$ ]. Available from: https://www. scirp.org/(S(czeh2tfqyw2orz553k1w0r45))/reference/ ReferencesPapers.aspx?ReferenceID $=746327$.

12. Ohri P, Singh H, Singh S, Mittal R, Neki N. Correlation of mammography and sonography in palpable breast lesions. Int J Curr Res Med Sci. 2017;3(7):30-7.

13. Prasad SN, Houserkova D. A comparison of mammography and ultrasonography in the evaluation of breast masses. Biomed Pap Med Fac Univ Palacky Olomouc Czech Repub. 2007;151(2):315-22.

14. Boyd NF, Rommens JM, Vogt K, Lee V, Hopper JL, Yaffe MJ, et al. Mammographic breast density as an intermediate phenotype for breast cancer. Lancet Oncol. 2005;6(10):798-808.

15. Ghebrehiwet M, Paulos E, Andeberhan T. The role of combined ultrasonography and mammography in the diagnosis of breast cancer in Eritrean women with paplable abnormalities of the breast. J Eritrean Med Associat. 2007;2(1):1-6.
16. Murphy IG, Dillon MF, Doherty AO, McDermott EW, Kelly G, O'Higgins N, et al. Analysis of patients with false negative mammography and symptomatic breast carcinoma.J Surg Oncol. 2007;96(6):457-63.

17. Devolli-Disha E, Manxhuka-Kerliu S, Ymeri H, Kutllovci A. Comparative accuracy of mammography and ultrasound in women with breast symptoms according to age and breast density. Bosn J Basic Med Sci. 2009;9(2):131-6.

18. Kolb TM, Lichy J, Newhouse JH. Comparison of the performance of screening mammography, physical examination, and breast US and evaluation of factors that influence them: an analysis of 27,825 patient evaluations. Radiology. 2002;225(1):165-75.

19. Flobbe K, Kessels AG, Severens JL, Beets GL, de Koning HJ, von Meyenfeld MF, et al. Costs and effects of ultrasonography in the evaluation of palpable breast masses. Int $\mathrm{J}$ Technol Assess Health Care. 2004;20(4):440-8.

20. Moss HA, Britton PD, Flower CD, Freeman AH, Lomas DJ, Warren RM. How reliable is modern breast imaging in differentiating benign from malignant breast lesions in the symptomatic population? Clin Radiol. 1999;54(10):676-82.

21. Shetty MK, Shah YP, Sharman RS. Prospective evaluation of the value of combined mammographic and sonographic assessment in patients with palpable abnormalities of the breast. J Ultrasound Med. 2003;22(3):263-8.

\section{Source of Support: Nil; Conflict of Interest: None}

Submitted: 05-01-2020; Accepted: 20-02-2020; Published online: 29-02-2020 